L. Masiero, J.M. Rose

The role of the reference alternative in the specification of asymmetric discrete choice models

Quaderno N. 11-04

Decanato della Facoltà di Scienze economiche

Via G. Buffi, $13 \mathrm{CH}-6900$ Lugano 


\title{
The role of the reference alternative in the specification of asymmetric discrete choice models
}

\author{
Lorenzo Masiero \\ Institute for Economic Research (IRE) \\ Faculty of Economics \\ University of Lugano, Switzerland \\ lorenzo.masiero@usi.ch \\ John M. Rose \\ Institute of Transport and Logistics Studies (ITLS) \\ Faculty of Economics and Business \\ The University of Sydney, Australia \\ john.rose@sydney.edu.au
}

Version 1.0: 04 December 2010

Paper presented at the 10th Swiss Transport Research Conference (STRC), Ascona, September 2010

\begin{abstract}
Within the discrete choice modelling literature, there has been growing interest in including reference alternatives within stated choice survey tasks. Recent studies have investigated asymmetric utility specifications by estimating discrete choice models that include different parameters according to gains and losses relative to the values of the reference attributes. This paper analyses asymmetric discrete choice models by comparing specifications expressed as deviations from the reference point and specifications expressed in absolute values. The results suggest that the selection of the appropriate asymmetric model specification should be based on the type of the stated choice experiment.
\end{abstract}

Keywords: stated choice experiments, reference alternative, preference asymmetry, willingness to pay 


\section{Introduction}

Within the stated choice experiment literature, there has been growing interest in designing the experiment in respect to the individual reference alternative (Train and Wilson, 2008; Rose at al., 2008). In this context, respondents are firstly asked to describe a well-experienced alternative (i.e. a reference alternative) in terms of some predefined attributes. The attribute levels for all the hypothetical alternatives presented in the choice experiment are then based on the attribute values of the reference alternative. In particular, the attribute levels of the hypothetical alternatives are pivoted around the attribute values of the reference alternative according to positive and negative deviations, either expressed in absolute values or in percentage changes, previously defined in the experimental design. Most of the reference pivoted stated choice experiments use to also include a "zero level" in the design of the hypothetical alternatives, where the attribute associated to the hypothetical alternative takes the same value of the attribute associated to the reference alternative. The reference alternative can either be included as an available alternative to choose or not. In particular, for experiments that include the reference alternative, it is common practice to ask two choices per each choice task. The second choice applies whenever the reference alternative has been chosen in the first choice and it forces the choice between the hypothetical alternatives (for discussions see for example, Brazell et al., 2006; Rose and Hess, 2010).

Recent studies have investigated asymmetric utility specifications (or, more precisely, reference dependent utility specification) by estimating discrete choice models that include different parameters according to gains and losses relative to the values of the reference attributes (see for example, Hess et al., 2008; Lanz et al., 2009; Masiero and Hensher, 2010). The findings from these studies support the prospect theory assumption of loss aversion (Kahneman and Tversky, 1979), where negative deviations from the reference attribute value (i.e., losses) are evaluated more than positive deviations from the reference attribute value (i.e., gains). Reference dependent model specifications, other than outperform the classic symmetric model specifications, can capture different estimates of willingness to pay (WTP) and willingness to accept (WTA) due to their asymmetric nature. In particular, the identification of loss aversion leads to WTA estimates that are bigger in value than WTP (see Horowitz and McConnell (2002) for a review about the WTA-WTP discrepancy).

Within the asymmetric utility specification, the definition of gains and losses is typically expressed in the form of deviations from the reference values and both the utility function for the reference alternative and the hypothetical attribute values associated to the "zero level" are normalized to zero (assuming a reference pivoted stated choice experiment that includes both the reference alternative in the choice set and the "zero level" in the attribute levels setting). Nevertheless, it is also possible to specify gains and losses in absolute values without normalizing for the reference alternative, and hence allowing the parameters associated to the reference alternative to be estimated ${ }^{1}$, as proposed by Rose and Masiero (2010). In fact, in defining the prospect theory, Kahneman and Tversky (1979) state that the reference point should not necessarily be set to zero since it represents the asset position. It is hence reasonable to estimate both the coefficients associated to the reference values and the coefficients associated to gains and losses.

The aim of this paper is to analyse reference dependent discrete choice models by comparing utility specification expressed as deviations from the reference point and utility specification expressed in

\footnotetext{
${ }^{1}$ Deviations from the reference point are then computed in terms of marginal utilities.
} 
absolute values. Indeed, in a stated choice framework, the way the attribute levels are shown to the respondent can affect the way in which they will process the experiment. That is, if the levels are presented as deviations from the reference values the respondent is probably more willing to think in terms of deviations. On the other hand, if the attribute levels are presented as absolute values, even in the presence of a reference alternative, the respondent will more than likely think in terms of absolute values. Therefore, the comparison between asymmetric models specified in terms of deviations or absolute values is important in order to understand the specification that needs to be performed in applications involving reference dependent discrete choice model estimation.

Two empirical data sets are used in the analysis. The first data used in the analysis consists of a freight transport stated choice experiment carried out among Swiss logistics managers. The second data set involves a stated choice experiment conducted in Brisbane Australia involving respondents travelling from the city to the airport by taxi. Both studies involve the choice between two unlabeled alternatives designed with attributes levels pivoted around the reference values and "zero level" included, however the former experiment does not allow respondents to choose the reference alternative (i.e., respondents can only select from the two hypothetical alternatives), whereas the latter study does (i.e., respondents may select either the current route or one of the two hypothetical routes). Furthermore, the design setting for the former study lets the respondents visualize the attributes levels in terms of deviations whereas in the latter study the attributes levels are presented in absolute values. Using both data sets, the current investigation aims to provide a better understanding of the role played by the reference alternative in the estimation of reference dependent discrete choice models. Furthermore, the paper focuses on the identification of potential significant differences in the estimates of the marginal rate of substitution across the two asymmetric specifications proposed.

The paper is organized as follows. Section two describes the stated choice experiments and the design setting. In section three we provide an overview of reference dependent discrete choice models distinguishing by the utility specifications proposed in the analysis. The results are presented and discussed in section four. Finally, in section five we outline the conclusion and direction for further research.

\section{Data}

The data refers to a freight transport stated choice experiment conducted among Swiss logistics managers in 2003 and a stated choice experiment conducted in 2006 among taxi users travelling from Brisbane metropolitan area to the local airport. The first dataset referred to the evaluation of relevant service characteristics in freight transport (see Maggi and Rudel, 2008 for details) whereas the second dataset makes use of respondent provided data related to travel times and costs of a recent taxi trip to the airport in order to construct a route choice experiment.

\subsection{Freight Transport Study}

The description of the attributes and attribute levels of the stated choice experiment for the freight transport study is presented in Table 1. In particular, the freight transport services are represented by conventional origin-destination services and they are expressed as function of cost (CHF per transport service), time (hours per transport service), punctuality (percentage of transport services arriving on time per yearly) and damages (yearly percentage of transport services which register damages to the goods transported). The hypothetical alternatives included in the designs of the freight transport choice 
experiments have been created by pivoting the cost and time attributes levels around a reference alternative previously described by the logistics managers. The values for cost and time attributes were then presented to logistics managers in terms of deviations from the reference values ${ }^{2}$ whereas values for punctuality and damages were presented in absolute values for technical convenience (that is in order to avoid attributes levels above 100 percent for punctuality and below zero percent for damages). The levels associated to each attributes in the two datasets are shown in Table 1.

The collection of the data involved face-to-face interviews based on Computer Assisted Personal Interview (CAPI), where logistics managers were asked to indicate their preferred alternative in each choice task. Regarding the freight transport data, 35 firms operating in the food and wholesale sector were represented and a subset of the sample answered to the same experiment twice, discriminating for inbound and outbound across the two experiments. The resulting freight transport sample is composed by 60 valid experiments, representing 1200 binary choice observations ( 20 choice tasks per respondent).

Table 1. Description of the stated choice experiments - freight transport study

\begin{tabular}{lc}
\hline & Attributes and Levels \\
\hline Transport Cost (CHF) & $-40 \%,-20 \%$, Reference, $+20 \%,+40 \%$ \\
\hline Transport time (hours) & $-40 \%,-20 \%$, Reference, $+20 \%,+40 \%$ \\
\hline Transport Punctuality (\%) & $96 \%, 98 \%, 100 \%$ \\
\hline Damages (\%) & $6 \%, 4 \%, 2 \%$ \\
\hline \multicolumn{2}{c}{ Design } \\
\hline Experiment & Unlabeled \\
\hline Alternatives & Alternative A and Alternative B \\
\hline Reference in Design & Not included \\
\hline Number of Choice tasks & 20 \\
\hline
\end{tabular}

\subsection{Airport Taxi Route Choice Study}

The second data set consists of a sample of 99 respondents who had recently travelled from the Brisbane metropolitan area to the airport using a taxi service. Given that it is typical in Australia for those using taxi services to be asked which route they wish to take, particularly when their involves a toll, the respondents were presented with a route choice experiment consisting of the choice between their most recently travelled route (the reference alternative) versus two new competing routes. Using a face to face CAPI survey instrument, sampled respondents were first asked about the travel times in terms of various traffic conditions and costs in terms of fare and any tolls paid for their most recent taxi trip to the airport. Questions as to how much variation in travel times exist over repeated trips were also asked $\mathrm{o}$ each respondent. The information provided was then used to construct 16 choice tasks where the attribute levels of the reference alternative consisted of the values provided by the respondent from which the levels of the time and fare cost attributes for the competing routes were pivoted from. Note that the toll cost attribute of the hypothetical alternatives were not pivoted from the toll cost of the reference route, despite the fact that a toll may have been paid at the time the real trip had been taken (the average toll paid for the actual real trip reported in the data was Au\$0.51 with a standard deviation of Au\$1.08). The decision not to pivot the toll cost was taken due to the desire to study specific toll

\footnotetext{
${ }^{2}$ This is common practice in a freight transport choice experiment context given that logistics managers are familiar with percentage deviations.
} 
values in the experiment. Independent of how the levels were constructed, the levels of the attributes for all three alternatives were presented to the respondents as absolute values, unlike in the freight experiment where they were presented as deviations from the reference point. In total, 1584 choice observations were obtained for modelling purposes. The attributes and a description of the experiment are provided in Table 2.

Table 2. Description of the stated choice experiments - Airport travel study

\begin{tabular}{cc}
\hline & Attributes and levels \\
\hline Free flow travel time & $-20 \%, 0 \%, 20 \%, 40 \%$ \\
Slowed down travel time & $-25 \%, 0 \%, 25 \%, 50 \%$ \\
Stop/start travel time & $-25 \%, 0 \%, 25 \%, 50 \%$ \\
Travel time variability $(10-30$ mins $)$ & $\pm 0 \%, \pm 5 \%, \pm 10 \%, \pm 15 \%$ \\
Travel time variability $(30+$ mins $)$ & $\pm 0 \%, \pm 7.5 \%, \pm 15 \%, \pm 22.5 \%$ \\
Fare & $-40 \%,-10 \%, 0 \%, 20 \%, 50 \%$ \\
Toll (10 - 30 mins) & $\$ 0.00, \$ 0.70, \$ 1.30, \$ 2.00, \$ 2.70, \$ 3.40, \$ 4.00$ \\
Toll (30 - 45 mins) & $\$ 0.00, \$ 1.00, \$ 2.00, \$ 3.00, \$ 4.00, \$ 5.00, \$ 6.00$ \\
Toll (45 + mins) & $\$ 0.00, \$ 1.30, \$ 2.60, \$ 4.00, \$ 5.30, \$ 6.60, \$ 8.00$ \\
\hline Experiment & Design \\
Alternatives & Unlabeled Route Choice \\
Reference in Design & Recent Route, Route A, Rout B \\
\hline Number of choice observations & Included \\
\end{tabular}

In the current context, no statistical differences between the travel time parameters where found, and hence, the three time attributes were combined into a composite travel time attribute. Further, the travel time variability parameter was not found to be statistically significant in any model, and hence was dropped from the analysis. As, such, the final set of modelled attributes consists of a single time attribute and the fare and toll attributes.

\section{Methodology}

\subsection{Model Specifications}

Within the mixed logit model framework, the reference dependent utility function for individual $n$ associated to alternative $j$ is typically defined according to positive and negative deviations from the reference alternative values. In particular, in a pair-wise stated choice experiment that does not include the reference alternative in the choice set (e.g., the freight transport study in our context), the specification of the systematic part ${ }^{3}$ of the two utility functions is defined as follows

$$
\left\{\begin{array}{l}
V_{n(\mathrm{~A})}=A S C_{\mathrm{A}}+\sum_{k} \beta_{n k(d e c d e v)} x_{k(d e c d e v)}+\sum_{k} \beta_{n k(\text { inc dev })} x_{k(i n c d e v)} \\
V_{n(\mathrm{~B})}=\sum_{k} \beta_{n k(d e c d e v)} x_{k(d e c d e v)}+\sum_{k} \beta_{n k(\text { inc dev })} x_{k(\text { inc dev })}
\end{array}\right.
$$

where, $x_{k(d e c d e v)}=\max \left(x_{e f}-x_{k}, 0\right)$ and $X_{k(i n c d e v)}=\max \left(x-x_{r e f}, 0\right)$. In a stated choice experiment that includes the reference alternative in the choice set (e.g., the taxi route choice study in our context) the specification expressed in (1a) becomes

\footnotetext{
${ }^{3}$ The unobserved part is assumed to Independent and Identically Distributed (IID) extreme value type 1.
} 


$$
\left\{\begin{array}{l}
V_{n(j)}=A S C_{j}+\sum_{k} \beta_{n k(d e c d e v)} x_{k(d e c d e v)}+\sum_{k} \beta_{n k(i n c d e v)} x_{k(i n c d e v)} \\
V_{n(r e f)}=0
\end{array}\right.
$$

where, $x_{k(d e c ~ d e v)}=\max \left(x_{r e f}-x_{k}, 0\right)$ and $X_{k(i n c d e v)}=\max \left(x_{k}-x_{r e f}, 0\right)$.

A crucial property of reference dependent models is the possibility to capture loss aversion. Individuals are loss averse if they evaluate losses more than gains (Kahneman and Tversky, 1979). Therefore, loss aversion is verified if the coefficient associated to losses is greater than the coefficient associated to gains.

Models in (1a) and (1b) refer to the typical specification proposed in the literature (see for example, Hess et al., 2008; Masiero and Hensher, 2010). However, this does not exclude that we can specify the model in absolute values, as argued by Rose and Masiero (2010), and then computing the difference from the reference point in terms of marginal utilities. In this context, the utility specifications associated to the freight transport study are defined as follows

$$
\begin{gathered}
\left\{\begin{array}{l}
V_{n(\mathrm{~A})}=A S C_{\mathrm{A}}+\sum_{k} \beta_{n k(d e c a b s)} x_{k(d e c a b s)}+\sum_{k} \beta_{n k(i n c a b s)} x_{k(\text { inc abs })}+\sum_{k} \beta_{n k(r e f)} \mathrm{X}_{\mathrm{k}(r e f)} \\
V_{n(\mathrm{~B})}=\sum_{k} \beta_{n k(d e c a b s)} x_{k(d e c a b s)}+\sum_{k} \beta_{n k(\text { inc abs })} x_{k(i n c a b s)}+\sum_{k} \beta_{n k(r e f)} \mathrm{X}_{\mathrm{k}(r e f)}
\end{array}\right. \\
\text { where, } \\
x_{k(d e c a b s)}=\left(x_{k} \text { if } x_{k}<x_{r e f}, 0 \text { otherwise }\right) \\
x_{k(\text { inc abs })}=\left(x_{k} \text { if } x_{k}>x_{r e f}, 0 \text { otherwise }\right) \\
x_{k(r e f)}=\left(x_{k} \text { if } x_{k}=x_{r e f}, 0 \text { otherwise }\right)
\end{gathered}
$$

It should be noted that the specification (2a) for a reference pivoted choice experiment that does not include the reference alternative in the choice set is only possible if the hypothetical alternatives are unlabeled and if the "zero level" is considered in the design of the hypothetical alternatives. For an experiment that includes the reference alternative in the choice set, as the car driver study in our context, the asymmetric specification with the reference alternative values not normalized and gains and losses expressed in absolute values is always possible and defined as follows

$$
\left\{\begin{array}{l}
V_{n(j-1)}=A S C_{j}+\sum_{k} \beta_{n k(d e c a b s)} x_{k(d e c a b s)}+\sum_{k} \beta_{n k(i n c a b s)} x_{k(i n c a b s)} \\
V_{n(r e f)}=\sum_{k} \beta_{n k(r e f)} x_{k(r e f)}
\end{array}\right.
$$

where, $x_{k(d e c a b s)}=\left(x_{k}\right.$ if $x_{k}<x_{r e f}, 0$ otherwise $)$ and $x_{k(\text { inc abs })}=\left(x_{k}\right.$ if $x_{k}>x_{r e f}, 0$ otherwise $)$.

For models specified in (2a) and (2b), loss aversion can easily be proved by taking the deviations from the coefficients associated to the reference alternative values. In particular, the marginal utility normalized to zero for the coefficients associated to looses and gains are as follows 
$\tilde{\beta}_{\text {(gains) }}=-\beta_{(\text {ref })}+\beta_{\text {(gains Abs) }}$

$\tilde{\beta}_{(\text {losses })}=-\beta_{(\text {ref })}+\beta_{\text {(losses Abs })}$

As common practice within the mixed multinomial logit (MMNL) models estimation, the distribution assumed for the random parameters is the normal distribution. The estimate for a generic random parameter is then expressed as follows

$\beta_{n k}=\beta_{k}+\eta_{n k}$

where $\eta_{n k}$ is a random disturbance drawn from a Normal distribution which captures individual preference heterogeneity.

The estimation of the utility parameters is derived from the maximization of the following simulated log likelihood:

$L L_{n}=\sum_{n} \ln \frac{1}{R} \sum_{r} \prod_{s} \frac{\exp \left(\alpha_{i}+\sum_{k} \beta_{n k} x_{n s i k}\right)}{\sum_{j} \exp \left(\alpha_{j}+\sum_{k} \beta_{n k} x_{n s j k}\right)}$

where $s=1, \ldots, S$ represent the number of choice situations and hence the panel structure of the data, and $r=1, \ldots, R$ refers to the number of draws used for the identification of each random parameter. In this paper, 500 Halton draws are used ${ }^{4}$.

\subsection{Obtaining individual-specific conditional parameter distributions}

The parameters obtained from MMNL models represent population level estimates. Such parameters, in the form of parameter distributions, do not allow the analyst to easily determine where any particular individual's preference lies in the distribution. Fortunately, it is possible to construct estimates of individual-specific preferences. To do so, the individual's conditional distribution based (withinsample) on their observed choices may be derived (see e.g., Greene et al., 2005; Train, 2009). Estimation is undertaken through simulation to produce maximum simulated likelihood estimates for the conditional mean for each random parameter, as given in Equation (7).

$$
E\left(\beta_{n k}\right)=\frac{\sum_{r} \beta_{n k}^{r} \prod_{s=1}^{S_{n}} \frac{\exp \left(\alpha_{i}+\sum_{k} \beta_{n k} x_{n s i k}\right)}{\sum_{j} \exp \left(\alpha_{j}+\sum_{k} \beta_{n k} x_{n j k}\right)}}{\sum_{r} \prod_{s=1}^{S_{n}} \frac{\exp \left(\alpha_{i}+\sum_{k} \beta_{n k} x_{n s i k}\right)}{\sum_{j} \exp \left(\alpha_{j}+\sum_{k} \beta_{n k} x_{n j k i}\right)}},
$$

where $\beta_{n k}^{r}$ is the parameter obtained from the $r^{\text {th }}$ draw.

\footnotetext{
${ }^{4}$ See Train (2009) for details about Halton draws.
} 
The approach in Equation (7) can also be used to estimate the conditional variance of $\beta_{n}$ by Equation (8).

$$
\operatorname{var}\left(\beta_{n k}\right)=\sum_{r}\left(\beta_{n k}-E\left(\beta_{n k}\right)\right)^{2}
$$

The estimated conditional variance will be smaller than the average variance obtained simply by computing the sample variance from the estimated conditional means, as the latter is averaged over all the data in the sample while the former is averaged with respect only to the data for individual $n$ (see Greene et al., 2005; Train, 2009).

\subsection{Deriving willingness to pay and willingness to accept measures}

The derived WTP and WTA measures from models (1a), (1b) and (2a), (2b) are estimated as follows

$W T P=\frac{\beta_{n k(\text { gains })}}{\beta_{\text {cost }(\text { losses })}} ; W T A=\frac{\beta_{n k(\text { losses })}}{\beta_{\text {cost } t \text { gains })}}$,

where we use the means of the conditional parameter distributions obtained from Equation (7) in the numerator and fixed parameter estimates for the costs.

The stated choice experiment used in the second data set involved two separate cost attributes. To calculate the WTP measures for the reference alternative, a weighted average cost parameter was calculated using Equation (10).

$W A(\operatorname{Cos} t)=\frac{\left(\beta_{r c} x_{\mathrm{rc}}+\beta_{t c} x_{\mathrm{tc}}\right)}{\left(x_{\mathrm{rc}}+x_{\mathrm{tc}}\right)}$

where $\beta_{r c}$ and $\beta_{t c}$ are respectively the running cost and toll cost parameters, and $x_{\mathrm{rc}}$ and $x_{\mathrm{tc}}$ the associated attribute levels. Similar weighted average cost parameters were calculated for gains and losses so as to be able to compute the WTP and WTA measures given in Equation (10).

\section{Model results}

In this section we present the results obtained for the two reference dependent specifications, (1a) and (2a) for the freight transport dataset and (2a) and (2b) for the car drivers dataset, respectively. For each model we calculated the willingness to pay (WTP) and willingness to accept (WTA) measures estimated from the sample conditional mean. The comparison between the two specifications proposed is based on the model fits' indicators which include the log-likelihood at convergence, the Akaike's Information Criterion (AIC) and the McFadden $\rho^{2}$.

\subsection{Freight Transport Study}

Model results for the freight transport study are reported in Table 3. The first reported model (M1a) refers to the reference dependent model specification obtained according to positive and negative 
Table 3. Model results for freight transport study

\begin{tabular}{|c|c|c|c|c|}
\hline & \multicolumn{2}{|c|}{$\begin{array}{c}\text { M1a } \\
\text { Deviations }\end{array}$} & \multicolumn{2}{|c|}{$\begin{array}{c}\text { M2a } \\
\text { Abs Values + Ref }\end{array}$} \\
\hline & Par. & (t-ratio) & Par. & (t-ratio) \\
\hline \multicolumn{5}{|c|}{ Means for Random and Non-Random parameters } \\
\hline ASC Alternative A & 0.0481 & $(0.54)$ & 0.0758 & $(0.90)$ \\
\hline Damages & -0.4975 & $(-13.08)$ & -0.4709 & $(-13.17)$ \\
\hline Cost decrease Dev. & 0.0034 & $(5.81)$ & - & - \\
\hline Cost decrease Abs. & - & - & -0.0021 & $(-1.95)$ \\
\hline Cost increase Dev. & -0.0057 & $(-8.46)$ & - & - \\
\hline Cost increase Abs. & - & - & -0.0031 & $(-5.08)$ \\
\hline Time decrease Dev. & 0.0597 & $(1.72)$ & - & - \\
\hline Time decrease Abs. & - & - & -0.0261 & $(-0.74)$ \\
\hline Time increase Dev. & -0.1022 & $(-2.76)$ & & \\
\hline Time increase Abs. & - & - & -0.0424 & $(-2.15)$ \\
\hline Punctuality decrease Dev. & -0.3217 & $(-3.51)$ & - & - \\
\hline Punctuality decrease Abs. & - & - & 0.2985 & $(4.88)$ \\
\hline Punctuality increase Dev. & 0.3435 & $(3.18)$ & - & - \\
\hline Punctuality increase Abs. & - & - & 0.2994 & $(5.07)$ \\
\hline Cost Reference & - & - & -0.0024 & $(-3.04)$ \\
\hline Time Reference & - & - & -0.0402 & $(-1.62)$ \\
\hline Punctuality Reference & - & - & 0.2987 & $(4.99)$ \\
\hline \multicolumn{5}{|c|}{ Standard deviations for Random parameters } \\
\hline Time decrease Dev. & 0.0970 & $(2.26)$ & - & - \\
\hline Time decrease Abs. & - & - & 0.0329 & $(1.76)$ \\
\hline Time increase Dev. & 0.1310 & $(2.25)$ & & \\
\hline Time increase Abs. & - & - & 0.0509 & $(3.03)$ \\
\hline Punctuality decrease Dev. & 0.5308 & $(5.59)$ & - & - \\
\hline Punctuality decrease Abs. & - & - & 0.0063 & $(2.41)$ \\
\hline Punctuality increase Dev. & 0.4681 & $(4.42)$ & - & - \\
\hline Punctuality increase Abs. & - & - & 0.0104 & $(4.17)$ \\
\hline Time Reference & - & - & 0.0480 & $(3.33)$ \\
\hline Punctuality Reference & - & - & 0.0020 & $(0.40)$ \\
\hline \multicolumn{5}{|c|}{ WTP measures - conditional sample means } \\
\hline Travel Time & \multicolumn{2}{|c|}{10.70} & \multicolumn{2}{|c|}{8.50} \\
\hline Punctuality & \multicolumn{2}{|c|}{62.46} & \multicolumn{2}{|c|}{98.13} \\
\hline \multicolumn{5}{|c|}{ WTA measures - conditional sample means } \\
\hline Travel Time & \multicolumn{2}{|c|}{29.95} & \multicolumn{2}{|c|}{21.24} \\
\hline Punctuality & \multicolumn{2}{|c|}{90.55} & \multicolumn{2}{|c|}{141.86} \\
\hline \multicolumn{5}{|c|}{ Symmetric WTP measures for reference alternative - conditional sample mean } \\
\hline Travel Time & \multicolumn{2}{|c|}{-} & \multicolumn{2}{|c|}{16.84} \\
\hline Punctuality & \multicolumn{2}{|c|}{-} & \multicolumn{2}{|c|}{125.94} \\
\hline \multicolumn{5}{|c|}{ Model fits } \\
\hline Number of Observations & \multicolumn{4}{|c|}{1200} \\
\hline Log-L Restricted & \multicolumn{4}{|c|}{-831.776} \\
\hline Log-L at Convergence & \multicolumn{2}{|c|}{-511.93} & -53 & \\
\hline Number of Parameters & & & & \\
\hline AIC normalized & 0.8 & & & \\
\hline$\rho^{2}$ & 0.3 & & & \\
\hline Adj. $\rho^{2}$ & 0.3 & & & \\
\hline
\end{tabular}


deviations from the reference alternative attributes values. The second model (M2a) refers to the model specified without normalizing the reference values and keeping the attributes levels associated to gains and losses in absolute values.

Within the two models, the estimation of both the alternative specific constant and the coefficient associated to the damages experienced by the transport service are treated the same way. In particular, the alternative specific constant has been estimated for the alternative that was firstly visualized by the respondents, that is the first alternative from left to right in the choice task (alternative A), in order to check for the non-trading choice problem (see Hess et al., 2010 for details). However, for both models M1a and M2a, the alternative specific constant is not significantly different from zero excluding any inconsistent behaviour among respondents. The coefficient associated to the attribute reflecting the damages to the transport service has been set non-random and does not distinguish between gains and losses since for almost every logistics managers the reference values for damages is zero. For both models M1a and M2a, the coefficient associated to damages is negative as expected (i.e. the utility decrease as the damages increases).

The parameter estimates associated to gains and losses (and to reference values for model M2a) for time and punctuality attributes are assumed to be normal distributed whereas the coefficients associated to cost attribute are assumed to be fixed in order to avoid inconsistent estimates of marginal rate of substitutions (for a discussion see Revelt and Train, 2000). The mean estimates are in line with the expectation where coefficients associated to gains (time and cost decrease and punctuality increase) are positives and coefficients associated to losses are negatives (time and cost increase and punctuality decrease). For model M2a, this is not directly observable since the reference value is not zero but the coefficient associated to the reference attribute value itself. However, we could calculate the gains and losses around the reference values estimates according to Equations (3) and (4). In particular, we register an increase of the marginal utility associated to gains of $0.00027,0.01408$ and 0.00065 for cost, time and punctuality, respectively. On the losses domain we register a decrease of the marginal utility of -0.00068 for cost, -0.00224 for time and -0.00024 for punctuality. The coefficients' means associated to the reference values, estimated in model M2, are coherent that is negative for cost and time and positive for punctuality, and significantly different from zero, cost and punctuality at an alpha level of 0.05 whereas time at an alpha level of 0.15 . Loss aversion is verified, in both models M1a and $\mathrm{M} 2 \mathrm{a}$, for coefficients associated to cost, and for time attributes in model M1a, whereas the coefficient associated with the punctuality attribute does not capture any asymmetry.

Comparing the two models in terms of model fits, we observe that model M1a obtains a bigger loglikelihood at convergence even though model M2a includes more parameters, those associated to the reference alternative values, respectively. The better specification of model M1a is confirmed by the AIC index ${ }^{5}$ which is lower for M1a than for M2a and also by the significant increase registered by the $\rho^{2}$ which increases from 0.33 for model M2a to 0.38 for model M1a.

Looking at the WTP and WTA measures, we observe that the estimates derived from models M1a and $\mathrm{M} 1 \mathrm{~b}$ are in line with a previous study in a freight transport context, especially for the travel time attribute (see Masiero and Hensher, 2010). However, comparing the two models we register some differences. In particular, with respect to model M1a, models M2a indicates slightly lower estimates for WTP and WTA for travel time and significantly greater estimates for WTP and WTA for punctuality.

\footnotetext{
${ }^{5}$ The lower the AIC index is, the better the model fits the data.
} 


\subsection{Taxi Route Choice Study}

Model results for the taxi route choice study are reported in Table 4. As with the first study, two models are presented. The first model (M1b) refers to the reference dependent model specification. The second model (M2b) refers to the model specified without normalizing the reference values and keeping the attributes levels associated to gains and losses in absolute values.

Table 4. Model results for taxi route choice study

\begin{tabular}{|c|c|c|c|c|}
\hline & \multicolumn{2}{|c|}{$\begin{array}{c}\text { M1b } \\
\text { Deviations }\end{array}$} & \multicolumn{2}{|c|}{$\begin{array}{c}\text { M2b } \\
\text { Abs Values + Ref } \\
\end{array}$} \\
\hline & Par. & (t-ratio) & Par. & (t-ratio) \\
\hline \multicolumn{5}{|c|}{ Means for Random and Non-Random parameters } \\
\hline ASC Route A Alternative & 0.0185 & $(0.10)$ & -0.5674 & $(-1.05)$ \\
\hline ASC Route B Alternative & -0.0614 & $(-0.34)$ & -0.5694 & $(-1.06)$ \\
\hline Time decrease Dev. & 0.1226 & $(1.76)$ & - & - \\
\hline Time decrease Abs. & - & - & -0.0261 & $(-2.69)$ \\
\hline Time increase Dev. & -0.1600 & $(-7.94)$ & - & - \\
\hline Time increase Abs. & - & - & -0.0612 & $(-8.48)$ \\
\hline Fare decrease Dev. & 0.1983 & $(15.62)$ & - & - \\
\hline Fare decrease Abs. & - & - & -0.1692 & $(-12.89)$ \\
\hline Fare increase Dev. & -0.1044 & $(-7.92)$ & - & - \\
\hline Fare increase Abs. & - & - & -0.1786 & $(-18.70)$ \\
\hline Toll decrease Dev. & 0.1549 & $(1.22)$ & - & - \\
\hline Toll decrease Abs. & - & - & -0.0993 & $(-1.81)$ \\
\hline Toll increase Dev. & -0.0860 & $(-2.34)$ & - & - \\
\hline Toll increase Abs. & - & - & -0.3341 & $(-2.61)$ \\
\hline Reference Time & - & - & -0.0591 & $(-3.58)$ \\
\hline Reference Fare & - & - & -0.1741 & $(-8.77)$ \\
\hline Reference Toll & - & - & -0.3962 & $(-1.69)$ \\
\hline \multicolumn{5}{|c|}{ Standard Deviation for Random Parameters } \\
\hline Time decrease Dev. & 0.3254 & $(4.18)$ & - & - \\
\hline Time decrease Abs. & - & - & 0.0112 & $(0.94)$ \\
\hline Time increase Dev. & 0.1359 & $(8.02)$ & - & - \\
\hline Time increase Abs. & - & - & 0.0279 & $(6.33)$ \\
\hline Reference Time & - & - & 0.0621 & $(8.65)$ \\
\hline \multicolumn{5}{|c|}{ WTP measures - conditional sample means } \\
\hline Time & \multicolumn{2}{|c|}{$\$ 0.78$} & \multicolumn{2}{|c|}{$\$ 0.14$} \\
\hline \multicolumn{5}{|c|}{ WTA measures - conditional sample means } \\
\hline Time & \multicolumn{2}{|c|}{$\$ 1.33$} & \multicolumn{2}{|c|}{$\$ 0.33$} \\
\hline \multicolumn{5}{|c|}{ Symmetric WTP measures for reference alternative - conditional sample mean } \\
\hline Time & \multicolumn{2}{|c|}{ - } & \multicolumn{2}{|c|}{$\$ 0.34$} \\
\hline \multicolumn{5}{|c|}{ Model fits } \\
\hline Number of observations & \multicolumn{4}{|c|}{1584} \\
\hline Log-L Restricted & \multicolumn{4}{|c|}{-1740.2019} \\
\hline Log-L at Convergence & \multicolumn{2}{|c|}{-977.9970} & \multicolumn{2}{|c|}{-929.9326} \\
\hline Number of parameters & \multicolumn{2}{|c|}{10} & \multicolumn{2}{|c|}{26} \\
\hline AIC Normalized & \multicolumn{2}{|c|}{1.2475} & \multicolumn{2}{|c|}{1.1918} \\
\hline$\rho^{2}$ & \multicolumn{2}{|c|}{0.4380} & \multicolumn{2}{|c|}{0.4656} \\
\hline Adj. $\rho^{2}$ & \multicolumn{2}{|c|}{0.4344} & \multicolumn{2}{|c|}{0.4567} \\
\hline
\end{tabular}


Two ASC terms were estimated in both models, one each for the two hypothetical alternatives. As with the freight study models however, the ASC terms are not statistically significant in either model, suggesting that the means of the unobserved effects for all alternatives are not statistically different from one another. Also, similar to the freight study, we have treated the cost parameters as nonrandom, thus avoiding issues of having to take the ratios of two unconstrained distributions (see Daly et al., 2010). As such, only the time parameters were treated as random parameters assuming a Multivariate Normal distribution.

Examining model M1b, the parameters associated with increased attribute levels relative to the base alternative are all statistically significant whereas the mean time and toll decrease parameters are not statistically significant. For the time parameter, this may be partly explained by the fact that the pivot levels were not symmetrical around zero percent, with more levels representing higher percentage deviations on the increase side than for a decrease in travel time. As such, respondents were exposed more often to increased travel times than decreased travel times, which may explain why they were more sensitive to increases than decreases. Likewise, the low average for the reference alternative toll cost is indicative of the fact that in reality, the majority of trips to the airport did not use a toll route, and hence, the bulk of respondents observed more increases in toll cost than decreases. Both decreases and increases in fare are detected in the model. Unlike the toll cost and time attributes, the fare attribute, whilst not perfectly symmetrical around zero percent deviation, has a wider range of negative deviations than the other attributes. This suggests that in order to detect the desired effects, symmetrical deviations around zero percent may be required, or if not possible, a wide range of both positive and negative deviations should be used.

Model M2b, which utilises the absolute values shown to respondents in modelling as opposed to the deviations from the reference alternative, provides a superior model fit for the data relative to model M1b, even after accounting for the increase in the number of parameters estimated due to the inclusion of reference specific attributes. In this model, both increases and decreases in time were found to have statistically significant impacts with increases in travel time relative to the reference alternative having a larger magnitude than decreases. This supports the hypothesis of asymmetrical preferences for gains and losses, at least for the time attribute. In terms of the fare attribute, both gain and loss effects relative to the reference alternative where also found within the data, although the differences in magnitudes are not as pronounced as with the time attribute. For the toll parameter however, only the parameter associated with increased tolls was found to be statistically significant, again reflecting the fact that within the data, very few actual trips used a tolled route and hence, not many observations have decreased tolls.

Examining the WTP and WTA values from the two models, as with the freight study, the WTA values are larger in magnitude than the WTP values. However, unlike the freight study which showed mixed results in terms of which model produced the larger values for the attributes, here model M1b which used the deviations rather than the absolute values in estimation produces both larger WTP and WTA values for time. Thus, whilst the ratio of WTA to WTP for model M1b is 1.71 compared to 2.36 for model M2b, the WTP for model M1b is 5.58 times larger for model M1b than it is for model M2b (\$0.78 compared to \$0.14) whilst the WTA for model M1b is 4.03 times larger for model M1b to model M2b (\$1.33 compared to \$0.33). Nevertheless, direct comparisons between the values reported from the two models should be taken with care. For example, consider a trip for which the travel time will increase from 10 minutes to 15 minutes. Under model M1b, on average, respondents would be willing to pay $\mathrm{Au} \$ 3.90(5 \times \mathrm{Au} \$ 0.78)$ to avoid the additional five minutes. In model M2b however, the 
WTP is calculated for the entire 15 minute journey and is thus worth Au\$2.10 (15×Au\$0.14). Thus, the ratio in this scenario between the WTP values for M1b to M2b would be 1.85. Changing the scenario to a trip of 20 minutes or an increase of 10 minutes changes the WTP values for models M1b and M2b to $\$ 7.80$ and $\$ 2.80$ respectively, or a ratio of 2.79 .

\section{Conclusions}

This paper has investigated asymmetric discrete choice models by comparing specifications expressed as deviations from the reference alternative values and specifications expressed in absolute values. The data used in the analysis refer to a freight transport stated choice experiment carried out among Swiss logistics managers and to an airport taxi route stated choice experiment conducted in Brisbane Australia. In particular, the design setting for the former study lets the respondents visualize the attributes levels in terms of deviations whereas in the latter study the attributes levels are presented in absolute values. The two asymmetric model specifications have been tested across the two empirical datasets. In particular, the asymmetric model specified in terms of deviations involved the normalization to zero of the reference alternative values whereas in the model specified in terms of absolute values the coefficients associated to the reference alternative attributes values were free to be estimated.

The results suggest an interesting finding. In particular, for the freight transport study the specification in terms of deviations is preferred to the specification in terms of absolute values whereas for the airport taxi route choice study the specification in terms of absolute values obtained the best model fits. This is in line with the hypothesis that the way the attribute levels are shown to the respondent affect the respondent rational. Furthermore, we observed significant difference on the WTP and WTA estimates obtained from the two model specifications.

Based on our results, the selection of the appropriate asymmetric model specification should be based on the type of the stated choice experiment. In particular, stated choice experiments that present the attributes values to the respondents in terms of deviations should normalize to zero the reference alternative values and express the specification according to deviation values. On the contrary, stated choice experiments that show the attribute values in terms of absolute values should include the reference attribute values into the model specification without normalizing it and estimate the marginal utility associated to the attributes values expressed in absolute values.

\section{References}

Brazell, J., Diener, C., Karniouchina, E., Moore, W., Séverin, V., Uldry, P., 2006. The no-choice option and dual response choice designs. Marketing Letters 17(4), 255-268.

Daly, A., Hess, S., Train, K., 2010. Assuring finite moments for willingness to pay in random coefficient models. Working Paper: http://elsa.berkeley.edu/ train/papers.html.

Greene, W.H., Hensher, D.A., Rose, J.M., 2005. Using Classical Simulation Based Estimators to Estimate Individual Willingness to Pay Values, in Alberini, A. and Scarpa, R. (eds.), Applications of Simulation Methods in Environmental and Resource Economics, Kluwer Academic Publisher, New York. 
Hess, S., Rose, J.M., 2009. Should reference alternatives in pivot design SC surveys be treated differently? Environmental and Resource Economics 42, 297-317.

Hess, S., Rose, J.M., Hensher, D.A., 2008. Asymmetric preference formation in willingness to pay estimates in discrete choice models. Transportation Research Part E 44(5), 847-863.

Hess, S., Rose, J.M., Polak, J., 2010. Non-trading, lexicographic and inconsistent behaviour in stated choice data. Transportation Research Part D 15(7), 405-417.

Horowitz, J. McConnell, K.E., 2002. A Review of WTA-WTP Studies. Journal of Environmental Economics and Management 44, 426-47.

Kahneman, D., Tversky A., 1979. Prospect Theory: an analysis of decision under risk. Econometrica 47 (2), 263-291.

Lanz, B., Provins, A., Bateman, I., Scarpa, R., Willis, K., Ozdemiroglu, E., 2009. Investigating willingness to pay - willingness to accept asymmetry in choice experiments. Paper selected for presentation at the International Choice Modelling Conference 2009, Leeds (UK).

Masiero, L., Hensher, D.A., 2010. Analyzing loss aversion and diminishing sensitivity in a freight transport stated choice experiment. Transportation Research Part A 44(5), 349-358.

Revelt, D., Train, K.E., 2000. Customer-specific taste parameters and mixed logit. WP E00-274, Department of Economics, University of California at Berkeley, CA.

Rose, J.M., Bliemer, M.C.J., Hensher, D.A., Collins, A.T., 2008. Designing efficient stated choice experiments in the presence of reference alternatives. Transportation Research Part B 42(4), 395-406.

Rose, J.M., Hess, S., 2010. Dual-Response Choices in Pivoted Stated Choice Experiments. Transportation Research Record: Journal of the Transportation Research Board 2135, 25-33.

Rose, J.M., Masiero, L., 2010. A comparison of the impacts of aspects of prospect theory on WTP/WTA estimated in preference and WTP/WTA space. European Journal of Transport Infrastructure Research 10(4), 330-346.

Train, K., 2009. Discrete Choice Methods with Simulation, $2^{\text {nd }}$ Ed., Cambridge University Press, Cambridge.

Train, K., Wilson, W.W., 2008. Estimation on stated-preference experiments constructed from revealed-preference choices. Transportation Research Part B 42(3), 191-203. 


\section{QUADERNI DELLA FACOLTÀ}

1998:

P. Balestra, Efficient (and parsimonious) estimation of structural dynamic error component models

1999:

M. Filippini, Cost and scale efficiency in the nursing home sector : evidence from Switzerland

L. Bernardi, I sistemi tributari di oggi : da dove vengono e dove vanno

L.L. Pasinetti, Economic theory and technical progress

G. Barone-Adesi, K. Giannopoulos, L. Vosper, VaR without correlations for portfolios of derivative securities

G. Barone-Adesi, Y. Kim, Incomplete information and the closed-end fund discount

G. Barone-Adesi, W. Allegretto, E. Dinenis, G. Sorwar, Valuation of derivatives based on CKLS interest rate models

M. Filippini, R. Maggi, J. Mägerle, Skalenerträge und optimale Betriebsgrösse bei den schweizerische Privatbahnen

E. Ronchetti, F. Trojani, Robust inference with GMM estimators

G.P. Torricelli, I cambiamenti strutturali dello sviluppo urbano e regionale in Svizzera e

nel Ticino sulla base dei dati dei censimenti federali delle aziende 1985, 1991 e 1995

2000:

E. Barone, G. Barone-Adesi, R. Masera, Requisiti patrimoniali, adeguatezza del capitale e gestione del rischio

G. Barone-Adesi, Does volatility pay?

G. Barone-Adesi, Y. Kim, Incomplete information and the closed-end fund discount

$\mathrm{R}$. Ineichen, Dadi, astragali e gli inizi del calcolo delle probabilità

W. Allegretto, G. Barone-Adesi, E. Dinenis, Y. Lin, G. Sorwar, A new approach to check the free boundary of single factor interest rate put option

G.D.Marangoni, The Leontief Model and Economic Theory

B. Antonioli, R, Fazioli, M. Filippini, // servizio di igiene urbana italiano tra concorrenza e monopolio

L. Crivelli, M. Filippini, D. Lunati. Dimensione ottima degli ospedali in uno Stato federale

L. Buchli, M. Filippini, Estimating the benefits of low flow alleviation in rivers: the case of the Ticino River

L. Bernardi, Fiscalità pubblica centralizzata e federale: aspetti generali e il caso italiano attuale

M. Alderighi, R. Maggi, Adoption and use of new information technology

F. Rossera, The use of log-linear models in transport economics: the problem of

commuters' choice of mode

2001:

M. Filippini, P. Prioni, The influence of ownership on the cost of bus service provision in

Switzerland. An empirical illustration

B. Antonioli, M. Filippini, Optimal size in the waste collection sector

B. Schmitt, La double charge du service de la dette extérieure

L. Crivelli, M. Filippini, D. Lunati, Regulation, ownership and efficiency in the Swiss

nursing home industry

S. Banfi, L. Buchli, M. Filippini, Il valore ricreativo del fiume Ticino per i pescatori

L. Crivelli, M. Filippini, D. Lunati, Effizienz der Pflegeheime in der Schweiz 
2002:

B. Antonioli, M. Filippini, The use of a variable cost function in the regulation of the Italian water industry

B. Antonioli, S. Banfi, M. Filippini, La deregolamentazione del mercato elettrico svizzero e implicazioni a breve termine per l'industria idroelettrica

M. Filippini, J. Wild, M. Kuenzle, Using stochastic frontier analysis for the access price regulation of electricity networks

G. Cassese, On the structure of finitely additive martingales

2003:

M. Filippini, M. Kuenzle, Analisi dell'efficienza di costo delle compagnie di bus italiane e svizzere

C. Cambini, M. Filippini, Competitive tendering and optimal size in the regional bus transportation industry

L. Crivelli, M. Filippini, Federalismo e sistema sanitario svizzero

L. Crivelli, M. Filippini, I. Mosca, Federalismo e spesa sanitaria regionale : analisi empirica per i Cantoni svizzeri

M. Farsi, M. Filippini, Regulation and measuring cost efficiency with panel data models : application to electricity distribution utilities

M. Farsi, M. Filippini, An empirical analysis of cost efficiency in non-profit and public nursing homes

F. Rossera, La distribuzione dei redditi e la loro imposizione fiscale : analisi dei dati fiscali svizzeri

L. Crivelli, G. Domenighetti, M. Filippini, Federalism versus social citizenship :

investigating the preference for equity in health care

M. Farsi, Changes in hospital quality after conversion in ownership status

G. Cozzi, O. Tarola, Mergers, innovations, and inequality

M. Farsi, M. Filippini, M. Kuenzle, Unobserved heterogeneity in stochastic cost frontier models : a comparative analysis

2004:

G. Cassese, An extension of conditional expectation to finitely additive measures

$\mathrm{S}$. Demichelis, O. Tarola, The plant size problem and monopoly pricing

F. Rossera, Struttura dei salari 2000 : valutazioni in base all'inchiesta dell'Ufficio federale di statistica in Ticino

M. Filippini, M. Zola, Economies of scale and cost efficiency in the postal services : empirical evidence from Switzerland

F. Degeorge, F. Derrien, K.L. Womack, Quid pro quo in IPOs : why book-building is dominating auctions

M. Farsi, M. Filippini, W. Greene, Efficiency measurement in network industries : application to the Swiss railway companies

L. Crivelli, M. Filippini, I. Mosca, Federalism and regional health care expenditures : an empirical analysis for the Swiss cantons

S. Alberton, O. Gonzalez, Monitoring a trans-border labour market in view of liberalization : the case of Ticino

M. Filippini, G. Masiero, K. Moschetti, Regional differences in outpatient antibiotic consumption in Switzerland

A.S. Bergantino, S. Bolis, An adaptive conjoint analysis of freight service alternatives :

evaluating the maritime option

2005:

M. Farsi, M. Filippini, An analysis of efficiency and productivity in Swiss hospitals

M. Filippini, G. Masiero, K. Moschetti, Socioeconomic determinants of regional

differences in outpatient antibiotic consumption : evidence from Switzerland 
2006:

M. Farsi, L. Gitto, A statistical analysis of pain relief surgical operations

M. Farsi, G. Ridder, Estimating the out-of-hospital mortality rate using patient discharge data

S. Banfi, M. Farsi, M. Filippini, An empirical analysis of child care demand in Switzerland

L. Crivelli, M. Filippini, Regional public health care spending in Switzerland : an empirical analysis

M. Filippini, B. Lepori, Cost structure, economies of capacity utilization and scope in Swiss higher education institutions

M. Farsi, M. Filippini, Effects of ownership, subsidization and teaching activities on hospital costs in Switzerland

M. Filippini, G. Masiero, K. Moschetti, Small area variations and welfare loss in the use of antibiotics in the community

A. Tchipev, Intermediate products, specialization and the dynamics of wage inequality in the US

A. Tchipev, Technological change and outsourcing : competing or complementary explanations for the rising demand for skills during the 1980s?

2007:

M. Filippini, G. Masiero, K. Moschetti, Characteristics of demand for antibiotics in primary care : an almost ideal demand system approach

G. Masiero, M. Filippini, M. Ferech, H. Goossens, Determinants of outpatient antibiotic consumption in Europe : bacterial resistance and drug prescribers

R. Levaggi, F. Menoncin, Fiscal federalism, patient mobility and the soft budget constraint : a theoretical approach

M. Farsi, The temporal variation of cost-efficiency in Switzerland's hospitals : an application of mixed models

2008

M. Farsi, M. Filippini, D. Lunati, Economies of scale and efficiency measurement in Switzerland's nursing homes

A. Vaona, Inflation persistence, structural breaks and omitted variables : a critical view

A. Vaona, The sensitivity of non parametric misspecification tests to disturbance autocorrelation

A. Vaona, STATA tip : a quick trick to perform a Roy-Zellner test for poolability in STATA

A. Vaona, R. Patuelli, New empirical evidence on local financial development and growth

C. Grimpe, R. Patuelli, Knowledge production in nanomaterials : an application of spatial filtering to regional system of innovation

A. Vaona, G. Ascari, Regional inflation persistence : evidence from Italy

M. Filippini, G. Masiero, K. Moschetti, Dispensing practices and antibiotic use

T. Crossley, M. Jametti, Pension benefit insurance and pension plan portfolio choice

R. Patuelli, A. Vaona, C. Grimpe, Poolability and aggregation problems of regional innovation data : an application to nanomaterial patenting

J.H.L. Oud, H. Folmer, R. Patuelli, P. Nijkamp, A spatial-dependence continuous-time model for regional unemployment in Germany

2009:

J.G. Brida, S. Lionetti, W.A. Risso, Long run economic growth and tourism : inferring from Uruguay

R. Patuelli, D.A. Griffith, M. Tiefelsdorf, P. Nijkamp, Spatial filtering and eigenvector stability : space-time models for German unemployment data

R. Patuelli, A. Reggiani, P. Nijkamp, N. Schanne, Neural networks for cross-sectional employment forecasts : a comparison of model specifications for Germany

A. Cullmann, M. Farsi, M. Filippini, Unobserved heterogeneity and International

benchmarking in public transport

M. Jametti, T. von Ungern-Sternberg, Hurricane insurance in Florida

S. Banfi, M. Filippini, Resource rent taxation and benchmarking : a new perspective for the Swiss hydropower sector 
S. Lionetti, R. Patuelli, Trading cultural goods in the era of digital piracy

M. Filippini, G. Masiero, K. Moschetti, Physician dispensing and antibiotic prescriptions

2010:

Quaderno n. 10-01

R. Patuelli, N. Schanne, D.A. Griffith, P. Nijkamp, Persistent disparities in regional unemployment : application of a spatial filtering approach to local labour markets in Germany

Quaderno n. 10-02

K. Deb, M. Filippini, Public bus transport demand elasticities in India

Quaderno n. 10-03

L. Masiero, R. Maggi, Estimation of indirect cost and evaluation of protective measures

for infrastructure vulnerability : a case study on the transalpine transport corridor

Quaderno n. 10-04

L. Masiero, D.A. Hensher, Analyzing loss aversion and diminishing sensitivity in a freight transport stated choice experiment

Quaderno n. 10-05

L. Masiero, D.A. Hensher, Shift of reference point and implications on behavioral reaction

to gains and losses

Quaderno n. 10-06

J.M. Rose, L. Masiero, A comparison of prospect theory in WTP and preference space Quaderno n. 10-07

M. Filippini, M. Koller, U. Trinkner, Do opening hours and unobserved heterogeneity affect economies of scale and scope in postal outlets?

Quaderno n. 10-08

G. Guerra, R. Patuelli, R. Maggi, Ethnic concentration, cultural identity and immigrant self-employment in Switzerland

Quaderno n. 10-09

S. Lionetti, Tourism productivity : incentives and obstacles to fostering growth

Quaderno n. 10-10

G. Guerra, R. Patuelli, The influence of role models on immigrant self-employment : a spatial analysis for Switzerland

Quaderno n. 10-11

M. Filippini, L. Gonzalez, G. Masiero, Estimating dynamic consumption of antibiotics using panel data : the shadow effect of bacterial resistance

2011:

Quaderno n. 11-01

L. Masiero, J.L. Nicolau, Price sensitivity to tourism activities : looking for determinant factors

Quaderno n. 11-02

L. Masiero, J.L. Nicolau, Finding similar price preferences on tourism activities

Quaderno n. 11-03

L. Masiero, R. Maggi, Accounting for WTP/WTA discrepancy in discrete choice models :

discussion of policy implications based on two freight transport stated choice experiments Quaderno n. 11-04

L. Masiero, J.M. Rose, The role of the reference alternative in the specification of asymmetric discrete choice models 